\title{
Solid-State Cultivation of Edible Oyster Mushrooms, Pleurotus spp. under Laboratory Conditions
}

\author{
Anastasia A. Shnyreva1, Elena Y. Kozhevnikova², Artem V. Barkov², Alla V. Shnyreva1* \\ ${ }^{1}$ Department of Mycology and Algology, Faculty of Biology, Moscow Lomonosov State University, Moscow, Russia \\ ${ }^{2}$ Laboratory of Biotechnology, Gubkin Russian State University of Oil and Gas, Moscow, Russia \\ Email: *ashn@mail.ru
}

How to cite this paper: Shnyreva, A.A., Kozhevnikova, E.Y., Barkov, A.V. and Shnyreva, A.V. (2017) Solid-State Cultivation of Edible Oyster Mushrooms, Pleurotus spp. under Laboratory Conditions. Advances in Microbiology, 7, 125-136. https://doi.org/10.4236/aim.2017.72010

Received: November 14, 2016

Accepted: February 1, 2017

Published: February 4, 2017

Copyright (๑) 2017 by authors and Scientific Research Publishing Inc. This work is licensed under the Creative Commons Attribution International License (CC BY 4.0).

http://creativecommons.org/licenses/by/4.0/

\begin{abstract}
Oyster mushrooms of genus Pleurotus are well known as valuable edible mushrooms which are broadly cultivated in the world as well as wildly propagated in forests of the temperate climate zones including Russia. Indoor cultivation conditions adapted for a laboratory with non-specialized facilities were suggested for effective solid-state cultivation and fruit bodies' production of Pleurotus species. Seven of 9 Pleurotus species of different origin produced fruit bodies successfully. The best fructification was shown for species $P$. sajor-caju, P. ostreatus, and P. pulmonarius with fruit body yields of $74 \%, 72 \%$, and $61 \%$ by dry substrate weight in the first flushing cycle. Fruit bodies appeared in five to 10-day flushes. "Spawn run" stage was completed within 17 to 24 days, the longest colonization stage ( 26 days) being for the pink oyster, $P$. djamor. The cultivation parameters proposed in this study can be employed with ease for laboratory and "home" cultivation of oyster mushrooms. The species and strains' identification was confirmed by restriction analysis of ITS region of rRNA gene cluster. Molecular barcodes based on restriction enzyme (AluI, and BsuRI) profiles of ITS sequences were shown to be applicable for molecular genotyping of Pleurotus species of different origin.
\end{abstract}

\section{Keywords}

Oyster Mushrooms, Pleurotus, Cultivation, Fruit Bodies, Molecular Genotyping

\section{Introduction}

Oyster mushrooms of the genus Pleurotus (Fr.) Kumm. (phylum Basidiomycota, subphylum Agaricomycotina, class Agaricomycetes, order Agaricales, family Pleurotaceae) are well known as valuable edible mushrooms which are broadly 
cultivated in the world as well as wildly propagated in forests of temperate climate zones including Russia. Due to the high nutritional value, delicate taste, and variable vitamins and minerals content, oyster mushrooms rank second in terms of industrial cultivation worldwide after a white button mushroom, Agaricus bisporus [1] [2]. Pleurotus mushrooms are also characterized by valuable medicinal properties such as antitumor, antioxidant and hypolipidemic activities [3] [4] [5] [6]. At the same time, they are xylotrophic fungi that inhabit on dead or living wood, except for species P. eryngii (Fr.) Quel., which is a parasite on roots of umbelliferous plants [7]. Since oyster mushrooms are secreting cellulolytic and lignolytic enzymes, they can be used for biotechnological purposes [8]. The most common species which is used for food purposes worldwide is Pleurotus ostreatus (Fr.) Kumm. The other species such as $P$. pulmonarius (Fr.) Quel., P. sajor-caju (Fr.) Singer, P. eryngii (Fr.) Quel., P. djamor (Rumph. ex Fr.) Boedijn., P. citrinopileatus Singer, and P. cornucopiae (Paul.) Rolland are also attractive for consumption as food. However, there are some species which are not cultivated and edible, for example, $P$. calyptratus (Lindblad ex Fr.) Sacc., $P$. cystidiosus $\mathrm{O}$. K. Mill. and $P$. dryinus (Pers.) P. Kumm.; the latter two species form an anamorphic stage (asexual sporulation) in the life cycle that is not typical for most members of genus Pleurotus. In the literature, there is not much information on production or laboratory cultivation of these species.

The genus Pleurotus is characterized by a complex taxonomic structure and includes about 30 species. However, traditional taxonomic identification of some closely related species or twin-species with similar morphology based on macroand micromorphological characteristics is not always unambiguous. In our previous study, for distinguishing closely related species such as $P$. ostreatus, $P$. pulmonarius, and $P$. sajor-caju, we employed tests on sexual compatibility (monmon crosses) to identify interspecific reproductive barriers between the species [9] [10]. The phylogenetic tree of genus Pleurotus was also constructed based on ITS1-5.8 S-ITS2 sequences of rRNA gene cluster [11].

The aim of the present study was adaptation of laboratory conditions (with non-specialized facilities) for effective solid-state cultivation and fruit bodies production of commonly cultivated species of genus Pleurotus, as well as some exotic species, and to confirm the species taxonomic names of cultivated strains by molecular genotyping.

\section{Material and Methods}

\subsection{Mushroom Strains}

Fourteen strains of nine species of genus Pleurotus were used in the study. The strains were obtained from different collections and were collected in different habitats (Table 1). Among them, there were wild natural isolates as well as cultivated commercial oyster mushroom strains. All strains were subjected to sequencing of ITS region of the rDNA cluster, and obtained sequences were deposited into GenBank under accession numbers presented in Table 1 . The original Pleurotus strains together with DNA samples were deposited at Depository of 
Table 1. List of Pleurotus strains used in the work.

\begin{tabular}{lcccc}
\hline Species & Strain & Origin & Collection & ITS accession number \\
in GenBank
\end{tabular}

*Collections: MSU-Department of Mycology and Algology, Moscow Lomonosov State University; ZBS MSU-Zvenigorod Biological Station, Moscow State University; WUR_Plant Research International, University of Wageningen, The Netherlands; IBIK-M.G. Kholodny Institute of Botany NASU, Kiev, Ukraine; CCBAS-Culture Collection of Basidiomycetes, Institute of Microbiology, Academy of Sciences of the Czech Republic; UPNA-Departamento de Producción Agraria, Universidad Pública de Navarra, Pamplona, Spain.

Living Systems, Moscow Lomonosov State University and stored at Department of Mycology and Algology, MSU (collection name MSU_BIO_EBF).

\subsection{Fruit Bodies Production under Laboratory Conditions}

Mycelial cultures were routinely grown on $1.5 \%$ malt extract agar (MEA) in Petri dishes at temperature $25^{\circ} \mathrm{C}$. First, sterile mycelial inoculum (spawn inoculum) was prepared. $50 \mathrm{~g}$ of dry wheat grains were placed in a $250 \mathrm{ml}$-conical glass flask and poured with $70 \mathrm{ml}$ of water. Flasks were closed with cotton plugs and sterilized at $121^{\circ} \mathrm{C}$ for $30 \mathrm{~min}$. Then sterile moisturized grains were inoculated with 7-day mycelial culture grown on agar plates: 3 mycelial agar blocks of $1 \mathrm{~cm}^{3}$ per each flask. The flasks were incubated in the dark at $25^{\circ} \mathrm{C}$ for about two weeks until the wheat seeds were covered with the mycelium.

In the next stage, a substrate (wheat straw) for mushroom solid state cultivation was prepared in a glass jar ( $1 \mathrm{~L}$ volume) covered with a glass lid. The glass jars were filled with $75 \mathrm{~g}$ of wheat straw and $500 \mathrm{~mL}$ of water. After autoclaving at $121^{\circ} \mathrm{C}$ for $30 \mathrm{~min}$, sterile straw became soft and suitable for colonization by the fungus. Excess of water in the jars after autoclaving was removed. Then wet substrate was inoculated with Pleurotus spp. spawn: wheat grains colonized by the mycelium in the flasks were transferred into glass jars with sterile wheat straw followed by incubation. After spawning, the glass jars were moved to a spawn run chamber and incubated in the dark at $25^{\circ} \mathrm{C}$ till complete colonization 
of spawned substrate (a "spawn run" stage) and primordia appearance. It usually took up to 20 - 30 days. Preliminary cultivation conditions were selected during series of laboratory experiments conducted by author Shnyreva A.A. in the laboratory of Prof. U. Kuees (Georg-August University, Goettingen, Germany) [12]. All experiments on solid-state cultivation of oyster mushrooms were conducted in six replicates for each tested strain. To trigger the fruiting, jars were placed in a cultivation chamber at $10^{\circ} \mathrm{C}$ and 9-h artificial daylight illumination for 2 days (conditions of "cold shock" stimulation of fruiting) and then transferred to a cultivation chamber for fruiting cycle. Two sets of experiments were performed: 1 -at temperature $20^{\circ} \mathrm{C}$ and $9 \mathrm{~h}$ artificial daylight illumination (700 lux), simulation of indoor (room) conditions during winter period; 2 -at $25^{\circ} \mathrm{C}$ and $12 \mathrm{~h}$ lighting (1000 lux), simulation of indoor conditions during summer. Relative humidity in the cultivation chamber was maintained at $85-95 \%$ and aeration was adjusted to keep $\mathrm{CO}_{2}$ level at $800 \mathrm{ppm}(0.10 \%-0.14 \%)$.

Productivity of oyster mushroom strains were evaluated by two flushes of fruiting. To evaluate the yield of mushrooms produced, mature fruit bodies were weighed after cutting, and parameters of fruit bodies (cap and stipe size) were measured. The yield was estimated and expressed as a percentage of fresh weight of the harvest $(\mathrm{g}$ ) over the dry substrate weight $(\mathrm{g})$ used. Mature fruit bodies were also placed in Petri dishes to obtain spore prints (basidiospores' offspring). Experiments on mushroom cultivation were performed using facilities designed at the Laboratory of Fungal Biotechnology, Gubkin Russian State University of Oil and Gas.

\subsection{Statistical Analysis}

Data were processed using Statistica 9.0. The results are expressed as mean values \pm standard deviation (SD) of six replicates.

\subsection{Molecular Genotyping of Strains}

To confirm species identity of cultivated mushroom strains, molecular genotyping based on sequencing of the ITS1-5.8 S-ITS2 region of rRNA gene cluster was performed; and the data were compared with those received previously in our laboratory [11]. Extraction of DNA was performed from 5-day-old mycelial cultures by a standard protocol [13]. DNA was purified by precipitation with $96 \%$ ethanol and used further as a template for amplification. Amplification was performed on thermal cycler "Amply4" (Biokom, Russia) using Taq polymerase and a pair of standard primers: forward ITS1 (5'-TCCGTAGGTGAACCTGCGG-3') and reverse ITS4 (5'-TCCTCCGCTTATTGATATGC-3'). The conditions of amplification were elaborated earlier [10]. Sequencing of PCR products was performed from both ends with each of two primers (ITS1 or ITS4) used in the amplification by using a set of reagents ABI PRISM ${ }^{\otimes}$ BigDye $^{\mathrm{TM}}$ Terminator V. 3.1, with subsequent analysis of the sequenced products on the automated sequencer "Applied Biosystems 3730 DNA Analyzer", at Joint Research Center "Genome" (Institute of Molecular Biology, Russia). Analysis of newly obtained sequences 
was performed using programs Chromas (http://technelysium.com.au) and Mega 6 (http://www.megasoftware.net). Restriction enzyme digestion of ITS amplicons were performed using a standard protocol [13].

\section{Results and Discussion}

\subsection{Oyster Mushrooms Cultivation}

Some edible species of oyster mushrooms ( $P$. ostreatus, $P$. pulmonarius, $P$. sajor-caju, $P$. eryngii) are widely cultivated in greenhouses around the world. Cultivated strains of different species require different cultivation conditions and growing parameters. For example, subtropical species such as $P$. djamor and $P$. sajor-caju are grown at higher temperatures and longer daylight illumination [14]. Required humidity for the growing of most cultivated species is varied in the range of $84 \%$ - 96\% [14] [15]. One of the crucial parameters for fruit bodies' production is the concentration of $\mathrm{CO}_{2}$ in a cultivation chamber. At high concentrations of carbon dioxide, fruit bodies are usually smaller and of atypical morphology. Color of fruit body caps are affected by temperature regime: the higher the temperature, the lighter pigmentation of the fruit body caps [16] [17].

Fourteen commercial and wild-collected strains of nine different Pleurotus species were successfully cultivated under the standardized laboratory conditions proposed in this study. Among tested mushroom strains, there were species inhabited in different climate zones and, therefore, required different growing parameters such as temperature and daylight illumination cycle. For example, species $P$. ostreatus, $P$. pulmonarius, $P$. cornucopiae, $P$. calyptratus, and $P$. dryinus are predominated in temperate climate forests, whereas species $P$. djamor and $P$. sajor-caju are inhabited in more humid and warm subtropical environment. Nevertheless, seven out of 9 species tested in our laboratory were shown to produce fruit bodies with typical morphology and relatively high yield, performing two flushes of fruiting. Results of the oyster mushrooms cultivation in the glass jars are presented in Table 2.

Primordia and mature fruit bodies were obtained for the following species: $P$. ostreatus, $P$. pulmonarius, $P$. sajor-caju, P.djamor, P. cornucopiae, $P$. cystidiosus and $P$. calyptratus. All these species were shown to colonize intensively the wheat straw substrate, $P$. ostreatus and $P$. cystidiosus strains being more successful. "Spawn run" stage (defined as a period of time when the mycelium is colonizing the substrate) for wild isolates H-5 ( $P$. ostreatus) and AG55/466 ( $P$. cystidiosus) was completed in 17 days, whereas the other strains demonstrated complete substrate colonization within 21 - 24 days, the longest colonization stage (26 days) being for the pink oyster, $P$. djamor wild strain 1526 (Table 2). During the fruiting cycle of Pleurotus strains, fruit bodies appeared in five to 10 -day flushes, except for the pink oyster strain 1526. Its first flush was registered much later, on $22^{\text {nd }}$ day of incubation at $25^{\circ} \mathrm{C}$ and $12 \mathrm{~h}$ lighting (under the "summer" laboratory conditions).

Two flushing cycles were obtained for almost all strains tested, except for the 
Table 2. Fruiting cycle of Pleurotus strains under laboratory conditions (days) (mean \pm $\mathrm{SD})$.

\begin{tabular}{|c|c|c|c|c|}
\hline \multirow{2}{*}{ Species } & \multirow{2}{*}{ Strain } & \multirow{2}{*}{ Spawn run period } & \multicolumn{2}{|c|}{ Fruiting flush cycle } \\
\hline & & & $1^{\text {st }}$ flush & $2^{\text {nd }}$ flush \\
\hline \multirow{4}{*}{ P. ostreatus } & $\mathrm{N}_{001}{ }^{1}$ & $24 \pm 2$ & $8 \pm 1$ & $18 \pm 2$ \\
\hline & $\mathrm{N}_{001}{ }^{2}$ & $24 \pm 2$ & $6 \pm 1$ & $10 \pm 1$ \\
\hline & $\mathrm{H}-5^{1}$ & $17 \pm 1$ & $7 \pm 2$ & $17 \pm 1$ \\
\hline & $\mathrm{H}-5^{2}$ & $17 \pm 1$ & $5 \pm 1$ & $8 \pm 1$ \\
\hline \multirow{4}{*}{ P. sajor-caju } & $\mathrm{CS}-32^{1}$ & $23 \pm 2$ & $7 \pm 1$ & $11 \pm 2$ \\
\hline & $\mathrm{CS}-32^{2}$ & $23 \pm 2$ & $6 \pm 1$ & $10 \pm 1$ \\
\hline & $\mathrm{H}-1^{1}$ & $25 \pm 1$ & $7 \pm 1$ & $11 \pm 1$ \\
\hline & $\mathrm{H}-1^{2}$ & $25 \pm 1$ & $5 \pm 1$ & $10 \pm 1$ \\
\hline \multirow{4}{*}{ P. pulmonarius } & O9- $3^{1}$ & $24 \pm 1$ & $10 \pm 2$ & $9 \pm 2$ \\
\hline & $09-3^{2}$ & $24 \pm 1$ & $7 \pm 2$ & $8 \pm 2$ \\
\hline & $\mathrm{ZBS} 2012^{1}$ & $23 \pm 1$ & $10 \pm 1$ & $9 \pm 1$ \\
\hline & ZBS2012 2 & $23 \pm 1$ & $10 \pm 1$ & $9 \pm 1$ \\
\hline \multirow{2}{*}{ P. djamor } & $1526^{1}$ & $26 \pm 1$ & ND & ND \\
\hline & $1526^{2}$ & $26 \pm 1$ & $22 \pm 2$ & $23 \pm 3$ \\
\hline \multirow{4}{*}{ P. cornucopiae } & $\mathrm{H}-14^{1}$ & $20 \pm 1$ & $10 \pm 1$ & $16 \pm 2$ \\
\hline & $\mathrm{H}-14^{2}$ & $20 \pm 1$ & $10 \pm 1$ & $14 \pm 1$ \\
\hline & $88^{1}$ & $23 \pm 1$ & $10 \pm 1$ & $14 \pm 1$ \\
\hline & $88^{2}$ & $23 \pm 1$ & $7 \pm 1$ & $12 \pm 1$ \\
\hline \multirow{4}{*}{ P. calyptratus } & $\mathrm{C}-1^{1}$ & $21 \pm 1$ & $10 \pm 1$ & ND \\
\hline & $\mathrm{C}-1^{2}$ & $21 \pm 1$ & $9 \pm 3$ & ND \\
\hline & $1935^{1}$ & $21 \pm 1$ & $10 \pm 1$ & ND \\
\hline & $1935^{2}$ & $21 \pm 1$ & $8 \pm 2$ & ND \\
\hline \multirow{2}{*}{ P. cystidiosus } & AG 55/466 ${ }^{1}$ & $20 \pm 1$ & $10 \pm 2$ & ND \\
\hline & AG 55/466 ${ }^{2}$ & $17 \pm 2$ & $5 \pm 1$ & $30 \pm 2$ \\
\hline P. eryngii & $\mathrm{H}-7^{1,2}$ & $24 \pm 2$ & ND & ND \\
\hline P. dryinus & AG I $/ 467^{1,2}$ & $24 \pm 2$ & ND & ND \\
\hline
\end{tabular}

${ }^{*}$ Experimental series: ${ }^{1}$ cultivation at $20^{\circ} \mathrm{C}$ and $9 \mathrm{~h}$ lighting; ${ }^{2}$ cultivation at $25^{\circ} \mathrm{C}$ and $12 \mathrm{~h}$ lighting. ND, not detected.

species $P$. eryngii and $P$. dryinus. The species $P$. eryngii is known to be inhabited in hot semi desert climate zones and therefore, may require higher temperature and longer daylight exposure for successful fructification. Total yield of fresh fruit bodies over total dry substrate weight in the first flushing cycle was ranged between $44 \%$ and $74 \%$ (Table 3). The best fructification was shown for the species $P$. sajor-caju, $P$. ostreatus, and $P$. pulmonarius with the yield of fruit bodies of $74 \%, 72 \%$, and $61 \%$ by the dry substrate weight respectively in the first flushing cycle during the second experimental series (under the "summer" conditions). Maximum fruiting for almost all mushroom strains tested was observed 
in the first flush under the "summer" conditions. Remarkably, the yield of $P$. cystidiosus strain AG55/466 in the second flush reached 59\% over the dry substrate weight as compared to $47 \%$ productivity in the first flush (Table 3 ). Likewise, P. pulmonarius wild strains O9-3 and ZBS2012 which were collected in Moscow region demonstrated considerably high productivity (24\% and $34 \%$ respectively) in the second flushing cycle and $61 \%$, 56\% yields during the first flush (under the "summer" conditions). It should be mentioned that $P$. pulmonarius species is predominated in temperate climate forests in Moscow region in summer and, therefore, the cultivation laboratory conditions simulating natural

Table 3. Fruiting efficiency of Pleurotus strains.

\begin{tabular}{|c|c|c|c|c|c|c|c|}
\hline \multirow[b]{2}{*}{ Species } & \multirow[b]{2}{*}{ Strain ${ }^{\star}$} & \multicolumn{3}{|c|}{$1^{\text {st }}$ flush of fruiting } & \multicolumn{3}{|c|}{$2^{\text {nd }}$ flush of fruiting } \\
\hline & & $\begin{array}{c}\text { Cap } \\
\text { diameter, } \\
\mathrm{cm}\end{array}$ & $\begin{array}{c}\text { Stipe } \\
\text { length/diameter, } \\
\mathrm{cm}\end{array}$ & $\begin{array}{l}\text { Fruit bodies yield } \\
\text { over dry substrate } \\
\text { weight, } \%\end{array}$ & $\begin{array}{c}\text { Cap } \\
\text { diameter, } \\
\mathrm{cm}\end{array}$ & $\begin{array}{c}\text { Stipe } \\
\text { length/diameter, } \\
\mathrm{cm}\end{array}$ & $\begin{array}{c}\text { Fruit bodies yield } \\
\text { over dry substrate } \\
\text { weight, } \%\end{array}$ \\
\hline \multirow[t]{3}{*}{ P. ostreatus } & $\mathrm{N}_{001}{ }^{1}$ & $3.5 \pm 1.5$ & $3.0 \pm 0.5 / 1.0 \pm 0.5$ & 68 & $4.0 \pm 0.5$ & $2.5 \pm 0.5 / 1.0 \pm 0.5$ & 12 \\
\hline & $\mathrm{H}-5^{1}$ & $4.5 \pm 1.0$ & $4.5 \pm 2.0 / 1.0 \pm 0.5$ & 65 & $3.5 \pm 1.5$ & $2.0 \pm 0.5 / 0.5 \pm 0.1$ & 27 \\
\hline & $\mathrm{H}-5^{2}$ & $5.0 \pm 2.0$ & $5.5 \pm 1.5 / 1.0 \pm 0.5$ & 68 & $4.5 \pm 2.0$ & $2.5 \pm 0.5 / 0.75 \pm 0.2$ & 33 \\
\hline \multirow[t]{3}{*}{ P. sajor-caju } & $\mathrm{CS}-32^{1}$ & $5.5 \pm 1.5$ & $3.0 \pm 0.5 / 1.0 \pm 0.2$ & 65 & $2.0 \pm 0.5$ & $1.5 \pm 0.3 / 1.0 \pm 0.2$ & 5 \\
\hline & $\mathrm{CS}-32^{2}$ & $7.5 \pm 1.5$ & $4.0 \pm 1.0 / 1.0 \pm 0.5$ & 74 & $2.7 \pm 1.3$ & $2.0 \pm 0.5 / 0.7 \pm 0.3$ & 5 \\
\hline & $\mathrm{H}-1^{2}$ & $7.0 \pm 2.0$ & $4.5 \pm 0.5 / 1.0 \pm 0.5$ & 71 & $3.5 \pm 1.0$ & $2.0 \pm 0.5 / 1.0 \pm 0.2$ & 5 \\
\hline \multirow[t]{4}{*}{$\begin{array}{c}P . \\
\text { pulmonarius }\end{array}$} & O9- $3^{1}$ & $5.0 \pm 1.8$ & $5.0 \pm 2.0 / 1.0 \pm 0.5$ & 60 & $5.0 \pm 1.0$ & $5.0 \pm 1.0 / 1.0 \pm 0.3$ & 25 \\
\hline & O9- $3^{2}$ & $5.0 \pm 2.0$ & $6.0 \pm 3.0 / 1.0 \pm 0.5$ & 61 & $4.0 \pm 2.0$ & $6.0 \pm 2.0 / 1.0 \pm 0.5$ & 24 \\
\hline & ZBS2012 ${ }^{1}$ & $2.5 \pm 2.0$ & $4.2 \pm 0.5 / 0.8 \pm 0.2$ & 56 & $3.0 \pm 1.5$ & $4.0 \pm 1.5 / 1.0 \pm 0.5$ & 28 \\
\hline & ZBS2012 2 & $2.7 \pm 1.3$ & $4.2 \pm 0.8 / 0.5 \pm 0.2$ & 56 & $5.0 \pm 2.0$ & $5.0 \pm 1.5 / 1.0 \pm 0.5$ & 34 \\
\hline \multirow[t]{2}{*}{ P. djamor } & $1526^{1}$ & ND & $\mathrm{ND}$ & $\mathrm{ND}$ & ND & ND & ND \\
\hline & $1526^{2}$ & $6.5 \pm 3.5$ & $1.4 \pm 0.6 / 0.5 \pm 0.1$ & 52 & $4.5 \pm 2.5$ & $1.7 \pm 0.8 / 0.4 \pm 0.1$ & 13 \\
\hline \multirow[t]{3}{*}{$\begin{array}{c}P . \\
\text { cornucopiae }\end{array}$} & $\mathrm{H}-14^{1}$ & $4.5 \pm 1.0$ & $2.5 \pm 0.5 / 0.8 \pm 0.3$ & 49 & $3.5 \pm 1.0$ & $2.5 \pm 1.5 / 0.4 \pm 0.2$ & 10 \\
\hline & $88^{1}$ & $2.7 \pm 1.0$ & $3.0 \pm 0.5 / 0.9 \pm 0.3$ & 45 & $1.5 \pm 1.0$ & $3.0 \pm 1.0 / 0.4 \pm 0.2$ & 5 \\
\hline & $88^{2}$ & $3.0 \pm 1.0$ & $3.0 \pm 1.0 / 0.7 \pm 0.3$ & 49 & $2.0 \pm 1.0$ & $3.0 \pm 1.0 / 0.5 \pm 0.2$ & 5 \\
\hline \multirow[t]{4}{*}{$\begin{array}{c}P . \\
\text { calyptratus }\end{array}$} & $\mathrm{C}-1^{1}$ & $5.0 \pm 0.5$ & ND & 44 & ND & $\mathrm{ND}$ & ND \\
\hline & $\mathrm{C}-1^{2}$ & $5.5 \pm 0.5$ & ND & 52 & ND & ND & ND \\
\hline & $1935^{1}$ & $6.0 \pm 1.0$ & $\mathrm{ND}$ & 49 & ND & ND & $\mathrm{ND}$ \\
\hline & $1935^{2}$ & $8.0 \pm 2.0$ & ND & 53 & $\mathrm{ND}$ & $\mathrm{ND}$ & ND \\
\hline \multirow[t]{2}{*}{$\begin{array}{c}P . \\
\text { cystidiosus }\end{array}$} & AG55/466 1 & $5.0 \pm 1.5$ & $4.5 \pm 0.5 / 0.7 \pm 0.3$ & 46 & $7.0 \pm 0.0$ & $3.0 \pm 0.0 / 0.8 \pm 0.0$ & 37 \\
\hline & AG $55 / 466^{2}$ & $7.0 \pm 0.0$ & $6.5 \pm 0.0 / 0.7 \pm 0.0$ & 47 & $7.0 \pm 1.5$ & $3.5 \pm 0.5 / 1.2 \pm 0.3$ & 59 \\
\hline
\end{tabular}

${ }^{*}$ Experimantal series: ${ }^{1}$ cultivation at $20^{\circ} \mathrm{C}$ and $9 \mathrm{~h}$ daylight; ${ }^{2}$ cultivation at $25^{\circ} \mathrm{C}$ and $12 \mathrm{~h}$ daylight. ND, not determined. 
"summer" ones were the most appropriate for this species. Thus, growing parameters such as temperature and lighting cycle were proved to have a significant impact on the overall productivity of wild and commercial Pleurotus strains that was shown by other authors as well [14] [15].

Native to the tropics, the pink oyster mushroom, $P$. djamor produced fruit bodies only in the second experimental series with simulated "summer" conditions, i.e. $12 \mathrm{~h}$ day lighting and temperature $25^{\circ} \mathrm{C}$. As compared to other species analysed, the "spawn run" stage (colonization of substrate by the mycelium) was delayed and observed only on $26^{\text {th }}$ day with further fructification on $22^{\text {nd }}$ day (Table 2). However, the total yield of fruit bodies in the first flush was reached $52 \%$ that is comparable with productivity of $P$. cornucopiae and $P$. calyptratus species which are common in areas with temperate climate (Table 3 ). Thus, we did not observe much correlation between the "spawn run" time and mushroom yields as it was reported in some publications [18] [19].

$P$. calyptratus wild strains (C-1 and 1935), which are not cultivated and nonedible, produced fruit bodies with one flush of fructification only, taking $30-31$ days from the substrate inoculation to the first flush harvested (Table 2). P. cystidiosus (strain AG55/466), the only species within the genus Pleurotus which produces asexual (anamorphic) coremia-like structures [20] was shown to produce mature fruit bodies successfully in both flushing cycles with the productivity of $47 \%$ and $59 \%$ by weight of dry substrate and the shortest period of first fruiting flush (totally 22 days from the "seeding" of the substrate to the first flush) in the "summer" experimental series (Table 2). There is little information about commercial cultivation of $P$. cystidiosus, and, particularly in Russia, the species is not popular for cultivation for food purposes. It should be mentioned that solid-state cultivation conditions proposed in this study apparently were not optimal for all species tested. Thus, broadly world-cultivated the king oyster, $P$. eryngii (commercial strain $\mathrm{H}-7$ ) was failed to produce fruit bodies. According to recommendations on cultivation of this species, it requires lower temperatures $\left(10^{\circ} \mathrm{C}-15^{\circ} \mathrm{C}\right)$ to form primordia and temperature above $18^{\circ} \mathrm{C}$ for further fruiting cycle [21]. However, we were unable to obtain fruit bodies for $P$. eryngii even after incubation with cold shock $\left(10^{\circ} \mathrm{C}\right)$. It might be due to non-specific substrate employed for the cultivation, since it is usually recommended to use complex substrates, including oak sawdust, sunflower or cottonseed husks, or wheat straw supplied with straw of umbelliferae plants [21]. Fructification was also failed for the oak oyster mushroom, $P$. dryinus. This species is not cultivated, although edible. It is confined to Northern latitudes, and might require special conditions for fruiting initiation under laboratory conditions. Remarkably, in this study, for the first time, fruit bodies of species $P$. cystidiosus and $P$. calyptratus were obtained under standardized conditions of the laboratory cultivation.

\subsection{Molecular Genotyping}

Molecular barcodes (or DNA barcording) based on restriction analysis of ITS sequences of the rRNA gene cluster were developed for genotyping Pleurotus 
species. The aim of developing DNA barcoding system is to employ a short, effective and standardized gene region for identification of various species [22]. There are several approaches for searching and developing appropriate molecular barcodes. In our study, we employed an approach based on ITS1-5.8S-ITS2 region of rRNA gene cluster that is commonly used in the Fungi kingdom. ITS sequences are shown to be variable and species-specific in most fungal taxa [23]. Searching for appropriate bar-codes for Pleurotus species, we demonstrated that ITS sequences within the genus Pleurotus are differed in their length and variable enough to be used for species differentiation. For better between-species resolution, we proposed using a protocol based on restriction enzyme digestion of ITS sequences amplified by PCR. Moreover, the ITS amplicons' digestion with selected set of enzymes was shown helping to proceed molecular identification of species within the genus faster avoiding a laborious sequencing technique. A set of restriction enzymes (AluI, BsuRI, Hinfl, and EcoRI) were proposed and tested for identification and differentiation of the species within genus Pleurotus, including commonly cultivated species. A chart flow of species-specific restriction enzymes patterns ( $A l u \mathrm{I}$ and BsuRI), or molecular barcodes, for the species used in this study is presented in Figure 1. As seen, numbers and sizes of the restriction fragments are differed and unique for each species tested. The unique system of molecular barcoding was developed for 17 genotypes which were relevant to 18 Pleurotus species including the species presented in this study [24]. Based on our previous research combined employing ITS-based molecular markers and sexual compatibility tests (mating crosses) [9] [10], it was proved that the molecular approach is a reliable technique to confirm species taxonomic names of cultivated oyster mushrooms and to differentiate closely related species within genus Pleurotus, for example, P. pulmonarius and P. sajor-caju, P. cornucopiae and $P$. citrinopileatus [10]. Such species (also called as "twin-species") are often of similar, hardly distinguishable morphology and therefore, it is quite awkward to identify their species taxonomic status. That is why molecular techniques become handy and of certain importance.

\section{Conclusion}

Simple and flexible technique (standardized laboratory conditions) is suggested for solid-state cultivation of different edible mushrooms of genus Pleurotus (oyster mushrooms). Seven of 9 species produced fruit bodies successfully. The growing parameters proposed can also be employed with ease for indoor "home" cultivation of a variety of oyster mushrooms. The species taxonomic names of the cultivated oyster mushrooms were confirmed by employing molecular markers based on restriction analysis of ITS sequences (defined as molecular barcodes). Molecular barcodes were shown to be also applicable for differentiation of closely related Pleurotus species of similar morphology (twin-species). The molecular genotyping is of obvious importance for maintaining and periodical checking substantial mushroom culture collections in order to avoid mushroom strains misidentification and cross-contamination of deposited mu- 
P. ostreatus

667bp

P. pulmonarius

658bp

P. sajor-caju

658bp

P. calyptratus

681bp

P. djamor

702bp

P.cornucopiae

663bp

P. cystidiosus

$657 \mathrm{bp}$
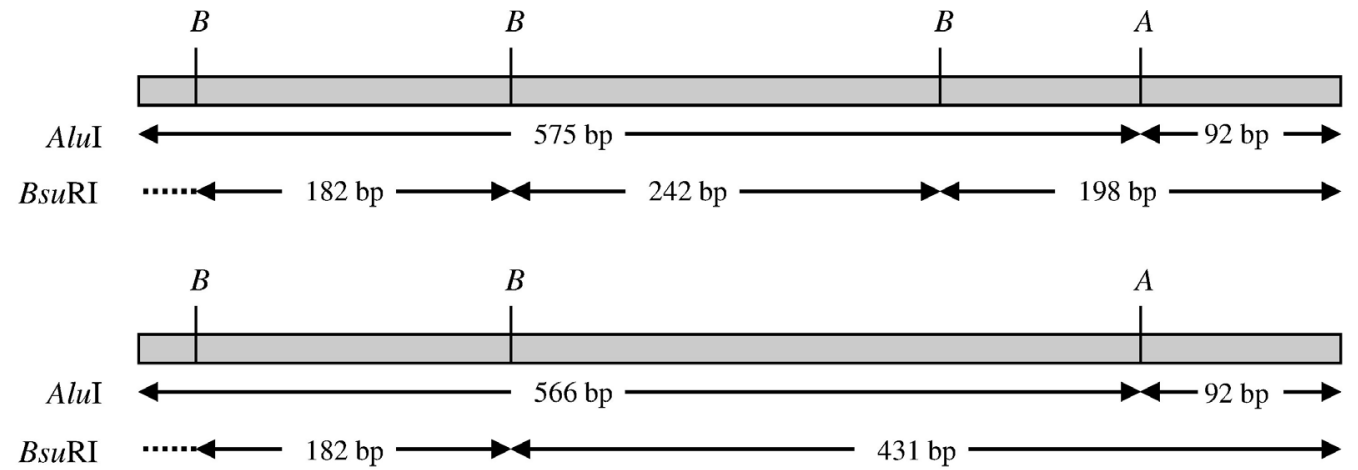

BsuRI

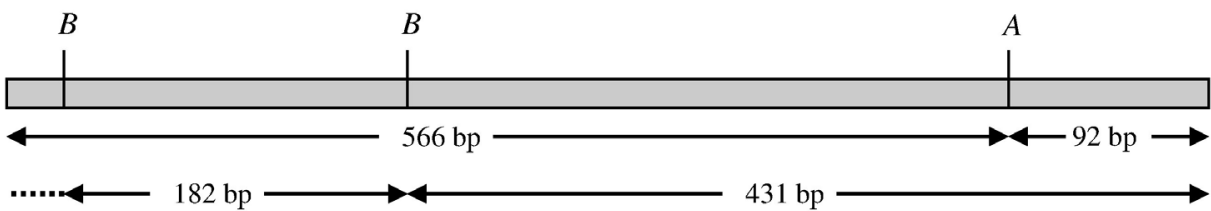

$B s u$ RI

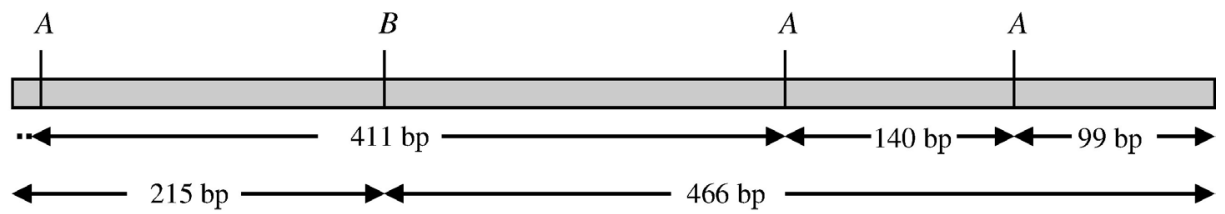

Alu

BsuRI

$215 \mathrm{bp}$

466 bp

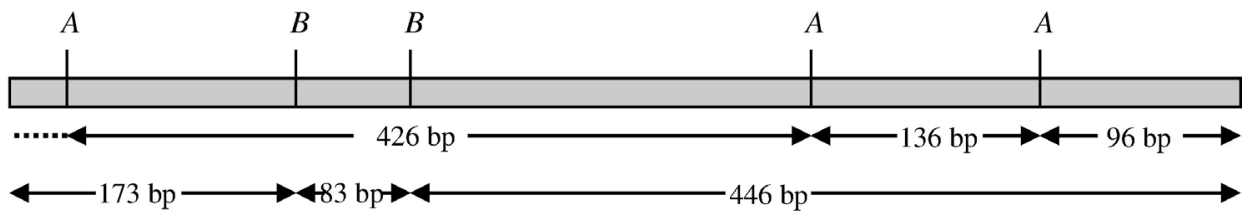

$B s u$ RI
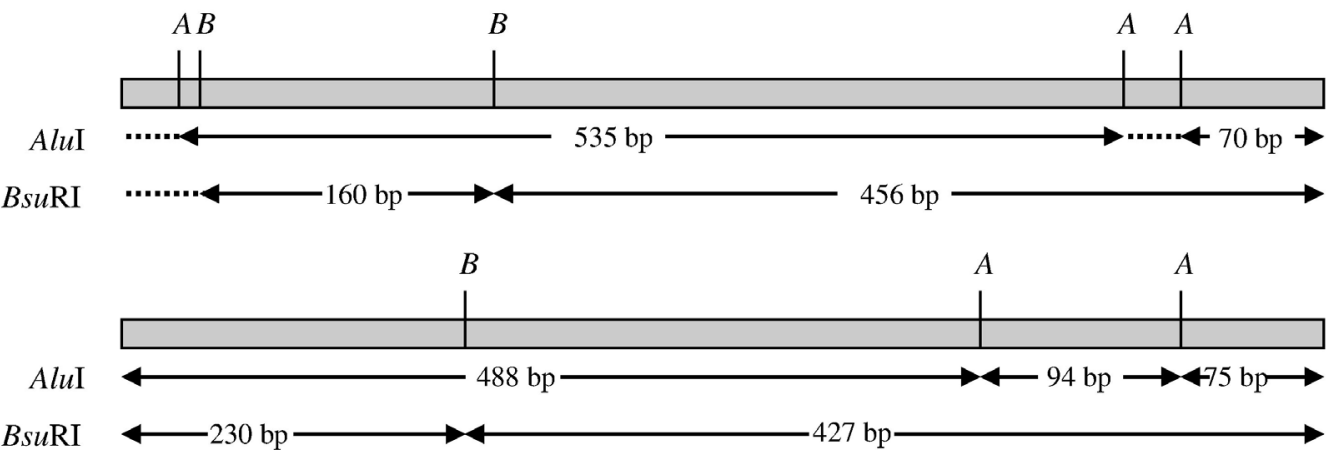

Figure 1. Molecular barcodes based on restriction enzyme digestion patterns of ITS1-5.8S-ITS2 region of rRNA gene cluster for Pleurotus species studied. ITS sequences for the restriction analysis were generated by PCR. ITS sequences within the genus Pleurotus are differed by their length (as indicated on the left in nucleotide base pairs, bp); number of restriction fragments in each pattern varies between 2 and 3 as detected in $1 \%$ agarose gel. Letters A and B on the top of each pattern corresponds to restriction enzyme sites: A = AluI, B = BsuRI; the fragment length is indicated in base pair, bp. The size and number of restriction fragments are species-specific and variable enough to be used for species differentiation.

shroom collections.

\section{Acknowledgments}

The authors thank colleagues for providing some strains of oyster mushrooms: 
M. Lomberg, Ph.D. (M.G. Kholodny Institute of Botany NASU, Kiev, Ukraine); Professor L. Homolka (Institute of Microbiology, Academy of Sciences of Czech Republic); Professor A. Sonnenberg (Plant Research International, University of Wageningen, The Netherlands), Professor U. Kues (University of Goettingen, Germany). Part of the work on culture collection maintenance and molecular genotyping was supported by RSF grant No. 14-50-00029. Spawn cultures preparation was supported by RFBR grant 15-54-05065. Solid-state mushroom cultivation was supported by grant of Ministry of Science and Education of Russian Federation (project 13.74.2014/K).

\section{References}

[1] Cheung, P. (2008) Nutritional Value and Benefits of Mushrooms. In: Cheung, P., Ed., Mushrooms as Functional Foods, Wiley \& Sons Inc., Hoboken, 71-110. https://doi.org/10.1002/9780470367285.ch3

[2] Baars, J., Sonnenberg, A., Mikosch, T. and Griensven, L. (2000) Development of a Sporeless Strain of Oyster Mushroom Pleurotus ostreatus. In: Griensven, L.B., Ed., Proceedings of the 15th International Congress on the Science and Cultivation of Edible Fungi, Rotterdam, 317-323.

[3] Wasser, S.P. and Weis, A.L. (1999) Therapeutic Effects of Substances Occurring in Higher Basidiomycetes Mushrooms: A Modern Perspective. Critical Reviews in Immunology, 19, 65-96.

[4] Zaidman, B.Z., Yassin, M., Mahajna, J. and Wasser, S.P. (2005) Medicinal Mushrooms Modulator of Molecular Targets as Cancer Therapeutics. Applied Microbiology and Biotechnology, 67, 453-468. https://doi.org/10.1007/s00253-004-1787-Z

[5] Reshetnikov, S.V., Wasser, S.P. and Tan, K.K. (2001) Higher Basidiomycota as a Source of Antitumor and Immunostimulating Polysaccharides (Review). International Journal of Medicinal Mushrooms, 3, 361-394. https://doi.org/10.1615/IntJMedMushr.v3.i4.80

[6] Ooi, V. (2008) Antitumor and Immunomodulatory Activities of Mushroom Polysaccharides. In: Cheung, P., Ed., Mushrooms as Functional Foods, Wiley \& Sons Inc., Hoboken, 147-198. https://doi.org/10.1002/9780470367285.ch5

[7] Garibova, L.V. and Sidorova, I.I. (1997) Fungi. Encyclopedia of Nature of Russia, ABF Publishing, Moscow, 159-214. (In Russian)

[8] Sánchez, C. (2010) Cultivation of Pleurotus ostreatus and Other Edible Mushrooms. Applied Microbiology and Biotechnology, 85, 1321-1337.

https://doi.org/10.1007/s00253-009-2343-7

[9] Shnyreva, A.V. and Shtaer, O.V. (2006) Differentiation of Closely Related Oyster Fungi Pleurotus pulmonarius and P. ostreatus by Mating and Molecular Markers. Russian Journal of Genetics, 42, 539-545. https://doi.org/10.1134/S1022795406050115

[10] Shnyreva, A.A., Sivolapova, A.B. and Shnyreva, A.V. (2012) The Commercially Cultivated Edible Oyster Mushrooms Pleurotus sajor-caju and P. pulmonarius Are Two Separate Species, Similar in Morphology but Reproductively Isolated. Russian Journal of Genetics, 48, 1080-1088. https://doi.org/10.1134/S1022795412110105

[11] Shnyreva, A.A. and Shnyreva, A.V. (2015) Phylogenetic Analysis of Pleurotus Species. Russian Journal of Genetics, 51, 148-157. https://doi.org/10.1134/S1022795415020131

[12] Shnyreva, A.A., Shnyerva, A.V. and Kues, U. (2013) The MatA Mating Type Locus 
of Pleurotus ostreatus. Proceedings of the 7 th International Medicinal Mushroom Conference, Beijing, 25-29 August 2013, 729-739.

[13] White, T.J., Bruns, T., Lee, S. and Taylor, J. (1990) PCR Protocols: A Guide to Methods and Applications. Academic Press, New York, 191-218.

[14] Stamets, P. (1993) Growing Gourmet and Medicinal Mushrooms. Ten Speed Press, Berkeley, 211-350.

[15] Royse, D.J. (1997) Specialty Mushrooms and Their Cultivation. Horticulture Reviews, 19, 59-97.

[16] Cotter, T. (2014) Organic Mushroom Farming and Mycoremediation. Chelsea Green Publishing, Vermont, 251-365.

[17] Sivolapova, A.B., Shnyreva, A.V., Sonnenberg, A. and Baars, I. (2012) DNA Marking of Some Quantitative Trait Loci in the Cultivated Edible Mushroom Pleurotus ostreatus (Fr.). Russian Journal of Genetics, 48, 383-389.

https://doi.org/10.1134/S1022795412040114

[18] Royse, D.J. (2002) Influence of Spawn Rate and Commercial Delayed Release Nutrient Levels on Pleurotus cornucopiae (Oyster Mushroom) Yield, Size, and Time to Production. Applied Microbiology and Biotechnology, 58, 527-531. https://doi.org/10.1007/s00253-001-0915-2

[19] Royse, D.J. and Schisler, L.C. (1987) Yield and Size of Pleurotus ostreatus and Pleurotus sajor-caju as Affected by Delayed-Release Nutrient. Applied Microbiology and Biotechnology, 26, 191-194. https://doi.org/10.1007/BF00253908

[20] Zervakis, G.I. (1998) Mating Competence and Biological Species within the Subgenus Coremiopleurotus. Mycology, 90, 1063-1074. https://doi.org/10.2307/3761281

[21] Kong, W.S. (2004) Description of Commercially Important Pleurotus Species. In: Choi, K.W., Ed., Mushroom Growers' Handbook 1: Oyster Mushroom Cultivation, MushWorld, Seoul, 54-61.

[22] Hebert, P.D.N., Cywinska, A., Ball, S.L. and de Waard, J.R. (2003) Biological Identifications through DNA Barcodes. Proceedings of the Royal Society B, 270, 313-321. https://doi.org/10.1098/rspb.2002.2218

[23] Nilsson, R.H., Kristiansson, E., Ryberg, M., Hallenberg, N. and Larsson, K.Y. (2008) Intra-Specific ITS Variability in the Kingdom Fungi as Expressed in the Internal Sequence Databases and Its Implications for Molecular Species Identification. Evolutionary Bioinformatics, 4, 193-201.

[24] Shnyreva, A.A. (2015) Fungi of Genus Pleurotus: Genotyping and Mating Type Loci Analysis. PhD Thesis, Reglet, Moscow, 53-81. 
Submit or recommend next manuscript to SCIRP and we will provide best service for you:

Accepting pre-submission inquiries through Email, Facebook, LinkedIn, Twitter, etc. A wide selection of journals (inclusive of 9 subjects, more than 200 journals)

Providing 24-hour high-quality service

User-friendly online submission system

Fair and swift peer-review system

Efficient typesetting and proofreading procedure

Display of the result of downloads and visits, as well as the number of cited articles Maximum dissemination of your research work

Submit your manuscript at: http://papersubmission.scirp.org/

Or contact aim@scirp.org 